\title{
1 Accessibility and the Ring of Unreliability
}

2 Mengying Cui

3 University of Minnesota

4 Department of Civil, Environmental, and Geo- Engineering

5500 Pillsbury Drive SE

6 Minneapolis, MN 55455 USA

7 cuixx242@umn.edu

8 David Levinson

9 RP Braun-CTS Chair of Transportation Engineering

10 Director of Network, Economics, and Urban Systems Research Group

11 University of Minnesota

12 Department of Civil, Environmental, and Geo- Engineering

13500 Pillsbury Drive SE

14 Minneapolis, MN 55455 USA

15 dlevinson@umn.edu

163894 words +6 figures +0 tables $=5394$ words

17 July 20, 2015 


\section{ABSTRACT}

2 This study measures the variability of job accessibility via automobile for the Minneapolis-St. Paul 3 region. The accessibility analysis uses cumulative opportunity measures. The travel times on the 4 network are tested at various level (10th percentile speed, 50th percentile speed, 90th percentile 5 speed) using the TomTom speed data for 2010. It is shown that accessibility varies widely day-to6 day as travel speeds on the network vary. Some parts of the region (a ring around the core) have 7 more volatility in accessibility (and are thus less reliable) than others. 


\section{INTRODUCTION}

2 Facing engineering failures such as bridge collapses, natural disasters like floods, and intentional

3 terrorist attacks, a progressively urbanized world has become increasingly vulnerable to interrup-

4 tions in its interconnected and interdependent networked transportation systems, including streets

5 and highways, transit routes, and truck-based supply chains. This research uses GPS data to in-

6 vestigate how transportation network performance depends on the variability of travel speeds, and

7 conjectures why some parts of the region are more reliable than others.

8 Recent efforts have assessed and validated GPS data from commercial vehicles for perfor-

9 mance measures highway traffic monitoring (1). The research team has developed a data process-

10 ing and analysis framework to generate performance measures from transit, truck, and auto GPS

11 data $(2,3,4)$. Much of the transportation system is brittle, so small disruptions to the system could

12 result in widespread effects $(5,6,7)$. The rise in nonrecurring congestion due to traffic incidents is

13 one example of how disruptions affect operations (8). Larger disruptions, such as Hurricane Sandy

14 or the 2014 Atlanta winter storm, propagate throughout highway, transit, and freight transportation 15 networks.

Transportation network structure has long been of interest to transport geographers, who considered it an outcome of an evolutionary process and an input into travel behavior and system performance $(9,10,11,12,13,14,15)$ and more recently physicists looking at the geography and spatial aspects of transportation networks to understand and reproduce their qualitative features $(16,17)$.

In transportation, the research team and others have picked up the research thread relating street network structure to travel behavior and system performance, such as the impacts of network topology and its evolution over time on commuting patterns (18), the relationship between network circuity and residential location choice relative to work (19), the relationship between network structure and travel distance (20) and travel time perception (21), how network structure and travel patterns affect the long-term vulnerability of road $(22,23)$ and transit networks $(24)$ and the relationship of road safety to street network characteristics (25).

Transportation systems are designed and constructed as interdependent layered networks. The hierarchy of services include short and long distance transportation services (e.g buses, freight) that make use of different and overlapping parts of the street network. The question of resilience is relevant to most of these layers. Transportation will be interrupted to a greater or lesser extent if the physical alignment is blocked (e.g. flood, snow, hazmat leak), if the road or bridge structure failures (e.g. potholes, sinkholes, heaving, a bridge collapse), if traffic control devices (signs, markings, signals) fail or deteriorate (e.g. an electrical outage, weathering), if vehicles fail to work (e.g. gasoline shortages (or electrical outages in the case of EVs), or system-wide vehicle recalls), if the driver is unable to drive the vehicle (e.g. strikes or illness), or if a service is interrupted (e.g. airplanes are grounded, trains or buses are cancelled, traveler information systems are disrupted (26)). Overuse of transportation facilities (congestion) may lead to a type of traffic failure that results when travel times increase beyond an acceptable level (or the area reachable in a given time shrinks). This can have consequences ranging from annoying to critical.

Within these layered networks are a hierarchy of roads and services. The hierarchy of roads is an emergent phenomenon $(27,28)$ that has become enmeshed in road and highway design - some roads are more significant (faster, more intensively used) than others. Similarly, transit systems are often designed with feeder routes connecting with regional routes, and freight systems have collector / distributor networks (local delivery networks) that connect to a long distance sys- 
1 tem. This hierarchical arrangement is also common in other networked utility systems (electrical,

2 natural gas, water, etc.).

\section{DATA}

Several different sources of data are applied in this research.

The first is GPS speed data for the year 2010. Comprehensive GPS data have high spatial and temporal coverage on the most widely traveled links, and reflect the actual driving patterns of drivers with GPS data. While this may not be perfectly representative of the population as a whole, it is the best available data, and there is no reason to believe the speeds that are reported are systematically biased due to sampling. (It is possible that flows on the links estimated from GPS traces are biased by sampling drivers with GPS devices, which may not be typical). This study employs data from TomTom, which was acquired by the Metropolitan Council. The original data were collected by millions of GPS logging and navigation devices, while the speed data were aggregated and processed based on that (37).

TomTom speed data were organized based on road classifications, time periods and speed percentiles. For 8 Functional Roadway Classification (FRC), speed data were separated into 4 groups, in which FRC0 to FRC4 were grouped into one dataset. For different time periods, considering the traffic properties, the time of a day was divided into seven parts, including Overnight, Morning Peak Hours (Two parts), Mid-Day, Evening Peak Hours (Two Parts) and Evening. Moreover, for each group, different percentiles of speed measurements, from 5th percentile to 95th percentile, in the same time period of a day were joined in the same databases. The 5 th percentiles speed shows the speed on links in the times which were the fastest 5 percent of those recorded, while the 95th percentile speeds similarly stands for the lowest speed.

The road network linked to TomTom data was obtained together with TomTom speed data from TomTom by the Metropolitan Council, which was used as a map shape file. It could help to analysis the road network, like searching for the shortest travel time paths between certain origins and destinations, based on the link speed.

The second data source that we used is TIGER/Line Shapefiles at the Block Level of Minnesota in 2010, which were acquired from the United States Census Bureau (38). The data contains 
1 selected geographic and cartographic information in Minnesota, which works in a GIS environ2 ment such as ArcGIS. In our research, the features in Twin Cities were selected from Minnesota's 3 Block level based on locations, and the centroids of each block were extracted as the origins and 4 destinations that we used to measure the accessibility.

\section{METHODS}

12 The Cumulative Opportunity Measure $(40,41)$ is the most basic method to calculate accessibility. The Cumulative Opportunity measure counts the number of opportunities (destinations) within a given travel time threshold using a certain transportation mode. For accessibility to jobs, the opportunity refers to the number of jobs. While there are many more sophisticated measures (such as a gravity and utility-based measures), they are not directly measurable, and do not have physical meaning. Hence, the cumulative opportunity measure for job accessibility is typically expressed as,

$$
\begin{gathered}
A_{i}=\sum_{j} O_{j} f\left(C_{i j}\right) \\
f\left(C_{i j}\right)= \begin{cases}1 & \text { if } C_{i j} \leq T \\
0 & \text { if } C_{i j}>T\end{cases}
\end{gathered}
$$

Where:

$A_{i}$ stands for the job accessibility of block $i$, $O_{j}$ stands for the number jobs in block $j$, $C_{i j}$ stands for the shortest travel time between block $i$ and block $j$, $T$ represents the travel time threshold.

The cumulative opportunity measure is a simple way to explain and calculate accessibility since its cost function is binary, which is determined by the predetermined time threshold and the cost. This measure of cumulative opportunity is calculated for each block using the data described in Section 3.

Based on the cumulative opportunity measure, the process of measurement was divided into two parts.

The first part was to use the ArcGIS to search for the shortest travel time path (using the network speeds from TomTom) and calculate the travel time for traveling from each origin to each destination. These OD travel times are used in the cumulative opportunity function by comparing them with the predetermined time threshold.

The second part was to join the job opportunity with the cost function to calculate the job accessibility for each origin. Considering the data scale of OD Matrix on the census block level, SQL Server were used to process the accessibility calculation. The results of job accessibility covers 54775 blocks in the seven counties of the Twin Cities. 


\section{RESULTS}

2 Figures 1 shows the job accessibility measurement with the time threshold of 20 minutes based on

3 the 50th percentile speed. The basic distribution pattern of job accessibility in the Twin Cities was

4 represented by this map.

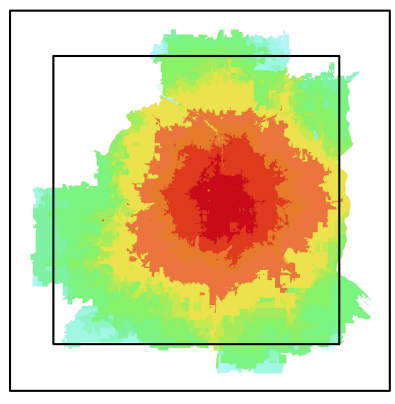

Jobs accessible within 20 minutes by car ( peak hour) based on 50th percentile speed

\begin{tabular}{|l|}
\hline $0-1,000$ \\
$1,000-2,500$ \\
$2,500-5,000$ \\
$5,000-7,500$ \\
$7,500-10,000$ \\
$10,000-25,000$ \\
$25,000-50,000$ \\
$50,000-75,000$ \\
$75,000-100,000$ \\
$100,000-250,000$ \\
$250,000-500,000$ \\
$500,000-750,000$ \\
$750,000-1,000,000$ \\
$1,000,000-$ \\
\hline Highways \\
\hline
\end{tabular}

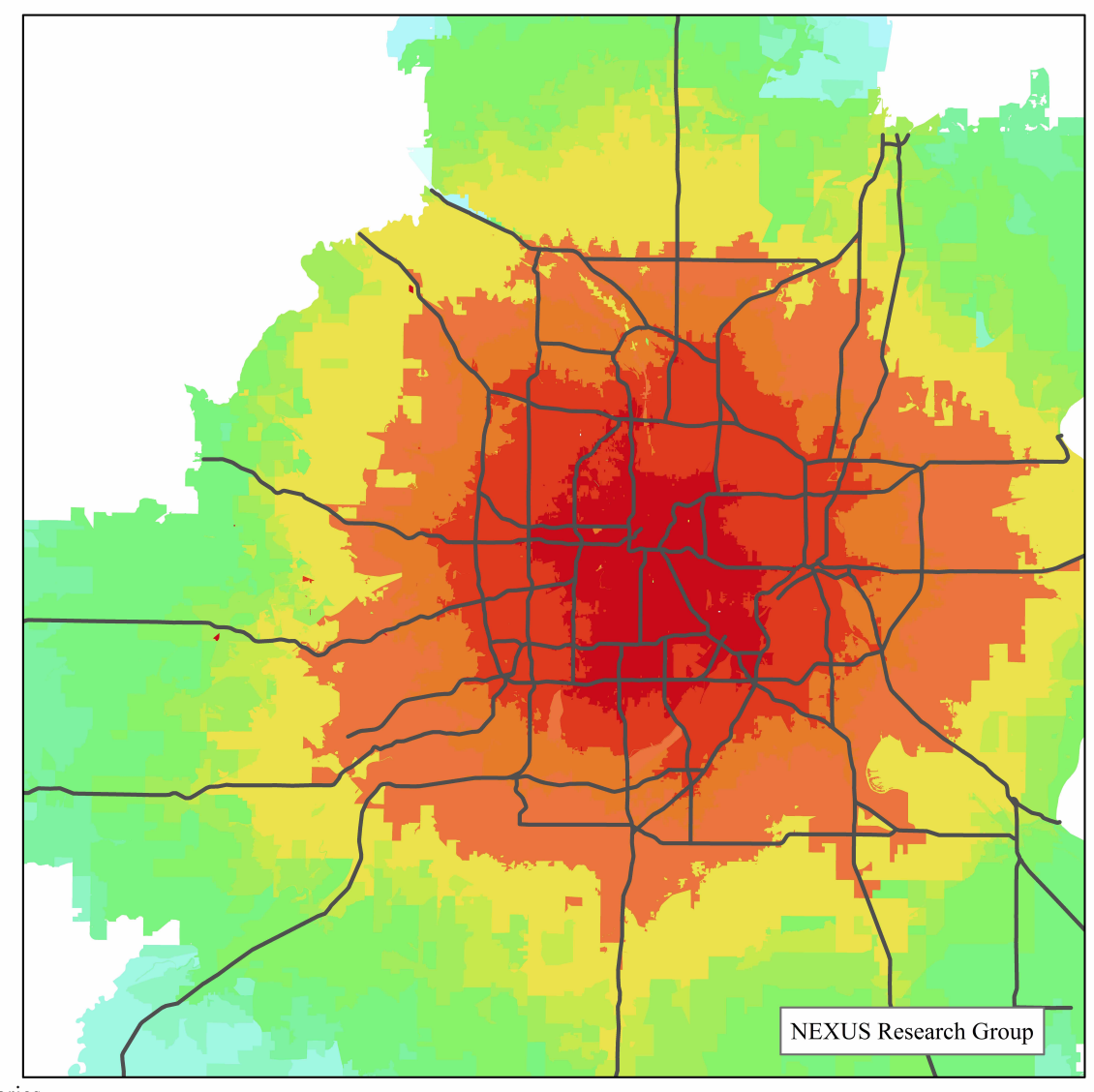

Zone Structure Displayed: Census Block Boundaries

Primary Data Sources: TomTom Speed Data, Metropolitan Council

FIGURE 1 : Job accessibility in 20 minutes based on the 50th percentile speed

The blocks with higher job accessibility are centered on downtown Minneapolis, which is visualized with the red color. With the increase of distance to the downtown area, the colors in Figure 1 change gradually from red to light blue, which illustrates the decline of job accessibility. In the exurban areas, the blocks have the lowest job accessibility. This condition comports with our understanding of the region, since the number of jobs in and around the downtown area are relative higher than in the far reaches, so suburbanites and exurbanites need more time to reach the same number of jobs. As a result, land prices are typically higher in central areas, as people and firms pay a premium for accessibility.

With different time thresholds, the results of job accessibility change significantly. Figures $2 \mathrm{a}, 2 \mathrm{~b}$, and $2 \mathrm{c}$ shows the job accessibility measurements with time thresholds of 20,30 , and 40 minutes respectively. In all of these figures, the speed on the network is still set as 50th percentile speed. 


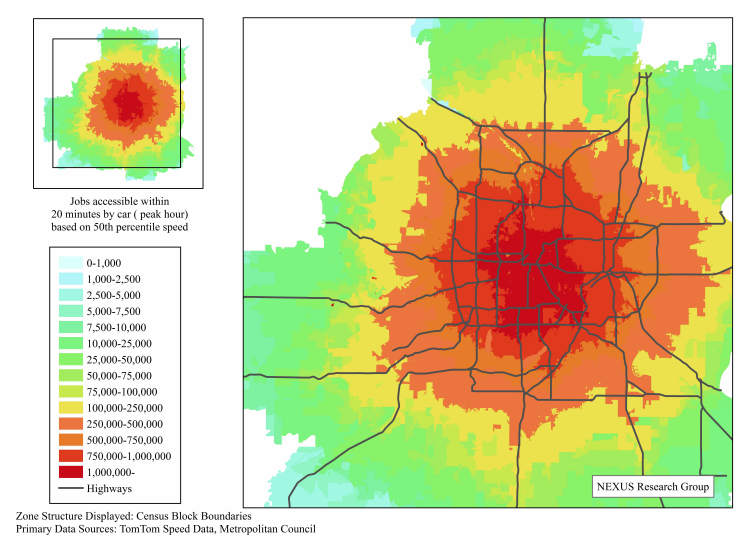

(a) Job accessibility in 20 minutes based on the 50th percentile speed

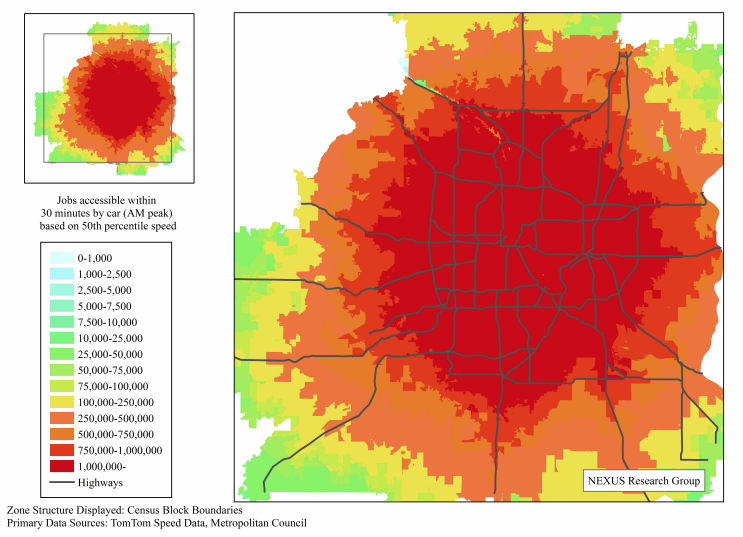

(b) Job accessibility in 30 minutes based on the 50th percentile speed

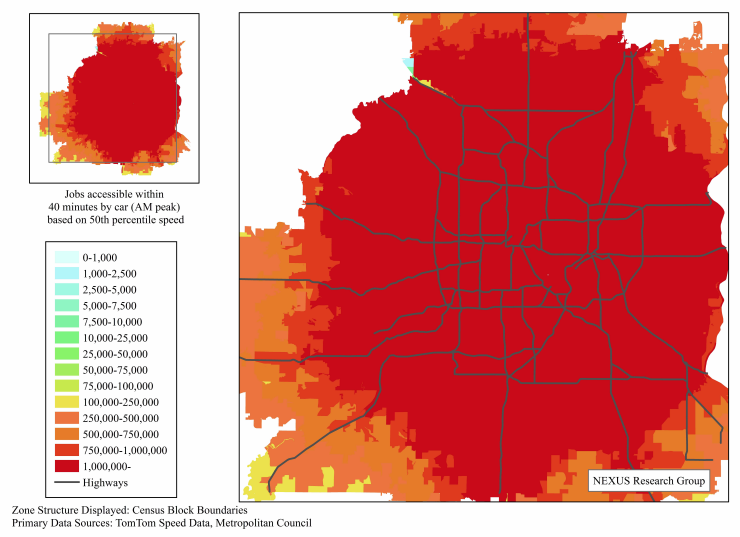

(c) Job accessibility in 40 minutes based on the 50th percentile speed

FIGURE 2 : Job accessibility in different time thresholds based on the 50th percentile speed

From Figures $2 \mathrm{~b}$ and $2 \mathrm{c}$ we see that an expansion of the red area centering on the downtown 2 occurs with the increase of time threshold. It is obvious that the most of the Twin Cities region has 3 a high job accessibility when the time threshold was set as 40 minutes. the job accessibility measurement is travel time. To find the distribution pattern of job accessibility based on different travel time, the 10th percentile speed and the 90th percentile speed of the road network were chosen to calculate the shortest travel time. We set the time threshold as 20 minutes. The changes of accessibility distribution are clearly shown in Figures $3 \mathrm{~b}$ and $3 \mathrm{c}$. When 10th percentile speed was set on the road network, more blocks show higher accessibility to jobs than 90th percentiles speed since the red area in Figure $3 b$ is larger than that in Figure 3c. The changes are also clearly reflected from Figure $4 a, 4 b$, and $4 c$, which shows the difference of job accessibility based on different percentile speed on the road network.

The explanation for this condition is also reasonable that more destinations are reachable on the road network with higher speed. Hence, the job accessibility measurements of 10th and 90th percentile speed have a larger differences than that of 10th and 50th, and 50th and 90th. Moreover, 


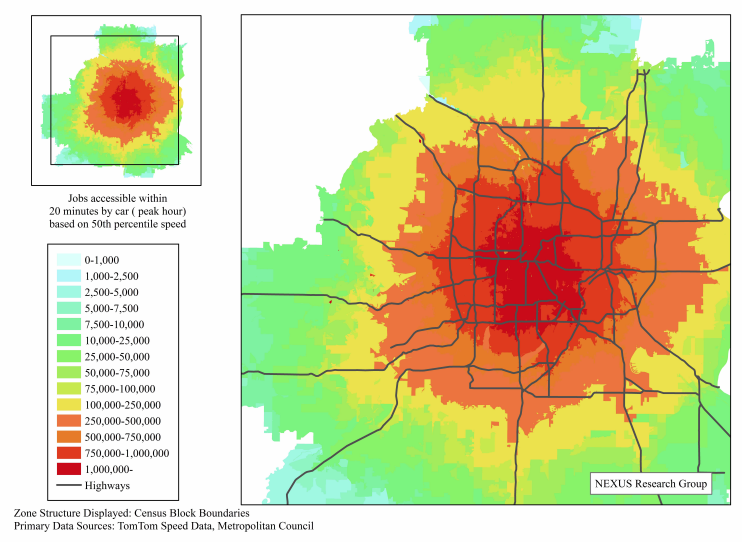

(a) Job accessibility in 20 minutes based on the 50th percentile speed

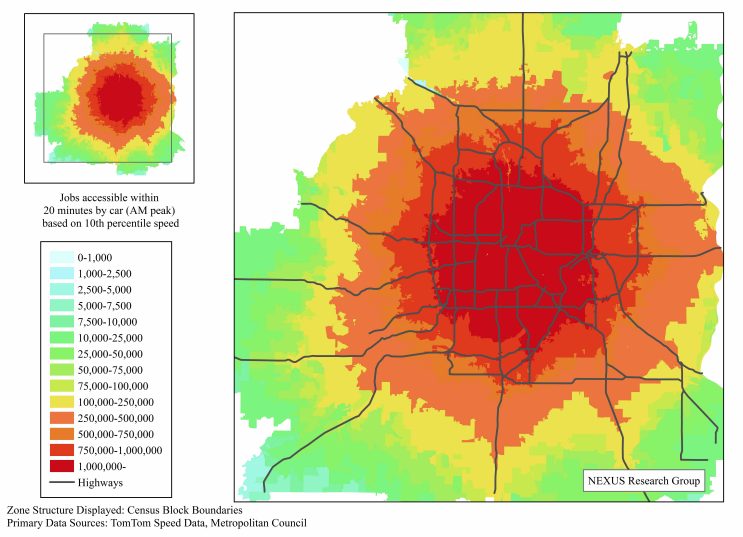

(b) Job accessibility in 20 minutes based on the 10th percentile speed

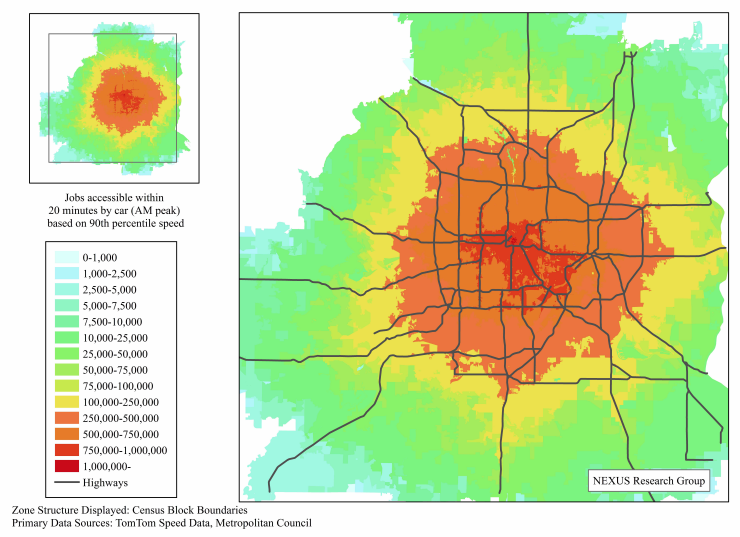

(c) Job accessibility in 20 minutes based on the 90th percentile speed

FIGURE 3 : Job accessibility in 20minutes based on the network with different percentile speed

1 Figures 4a, 4b, and 4c show a clear ring on each map.

This "Ring of Unreliability" shows where job accessibility within 20 minutes differs most greatly at the 10th and 90th percentile speeds. In short, the ring illustrates the origins that suffer most due to travel time variability. While we expected some areas to be more reliable than others, this ring pattern is especially noticeable.

Notably this is most prominent in the outer suburbs (along the I-494/I-694 beltway around the Twin Cities).

In part this is a feature of a cumulative opportunities measure. Some part of the region is just inside or just outside some number of jobs within 20 minutes, and since jobs are spatially concentrated, even a small perturbance in travel times will move some that were inside the threshold to just outside. However, the magnitude of the changes (several hundred thousands of jobs), is much greater than the difference between finding one job center within 20 minutes or just beyond 20 minutes. The region's largest job center, the Minneapolis Central Business District, has only 100,000 or so jobs (depending on definitions), about 6 percent of the region's total (42).

Figure 5 shows the patterns of "the ring of unreliability" in different time thresholds from 10 


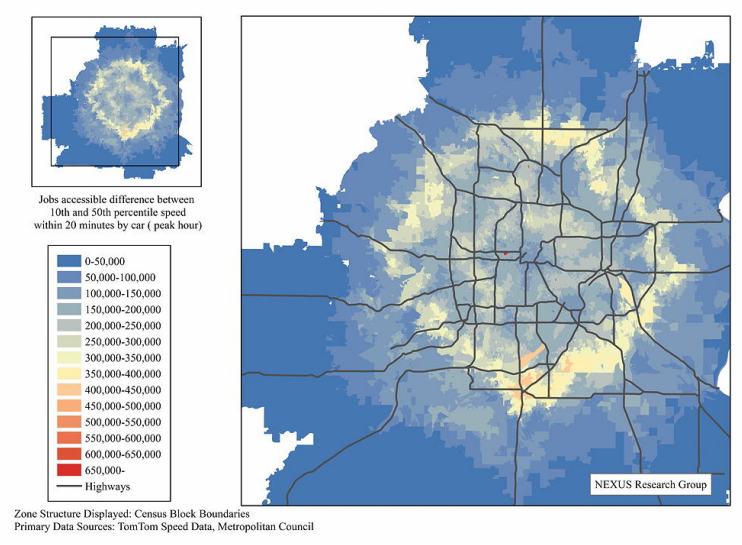

(a) The difference of job accessibility between 10th and 50th percentile speeds

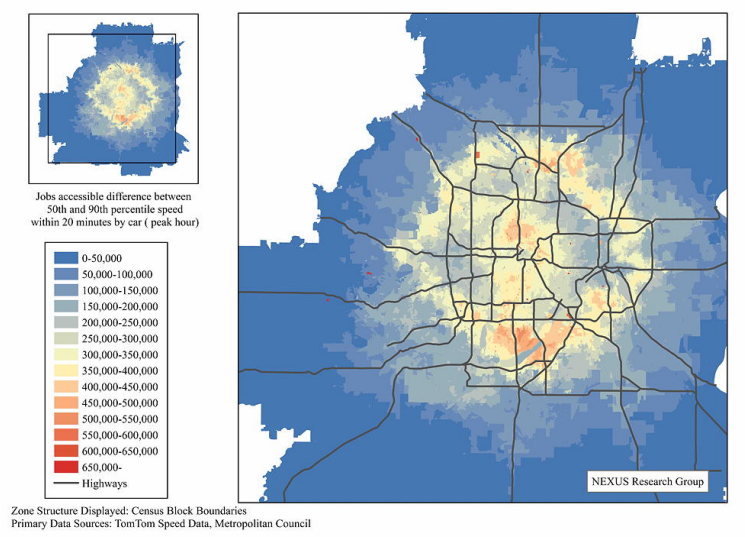

(b) JThe difference of job accessibility between (c) 50th and 90th percentile speeds

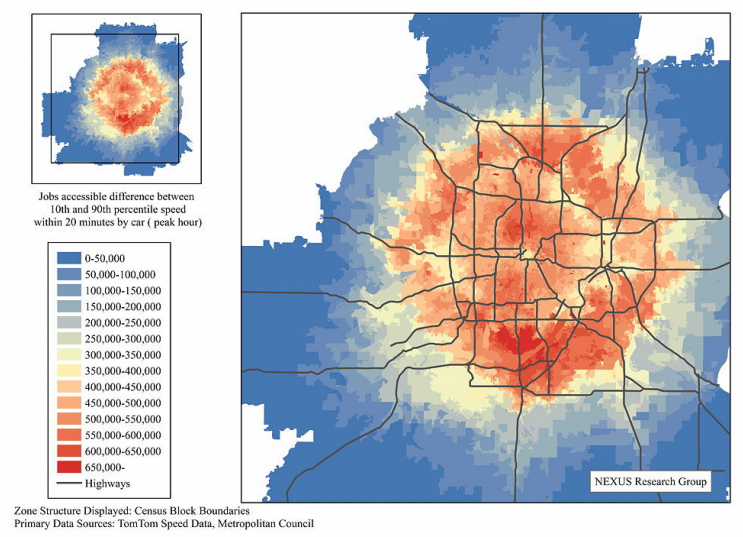

(c) The difference of job accessibility between 10th and 90th percentile speeds

FIGURE 4: The difference of job accessibility between networks with different percentile speeds

1 minutes to 60 minutes. Since people care more about the traffic delay in reality, only the differences

2 of job accessibility between 50th and 90th percentile speed are showed in Figure5. On each map,

3 the ring is showed clearly and noticeable, which proved the existence of the ring is not contrained

4 by the time threshold in a cumulative opportunity measure. However, from Figure5, we can see

5 that the time threshold affects the geographical distribution of the ring. A higher time threshold

6 would result in the spreading of the "unreliability ring" and moving the ring farther from the down 7 town area.

8

9

Time-weighted accessibility is a complete accessibility measure, which combined different time threshold with a different impedance (43). Based on the definition of time-weighted accessibility, it could be expressed as,

$$
A_{i, \text { time-weighted }}=\sum_{T=10}^{60}\left(A_{i, T}-A_{i, T-10}\right) e^{\beta * T}
$$

The differences of time-weighted accessibility between 50th and 90th percentile speed are showed in Figure 6. The " ring of unreliability" is also clearly showed on the map. And it distributes 


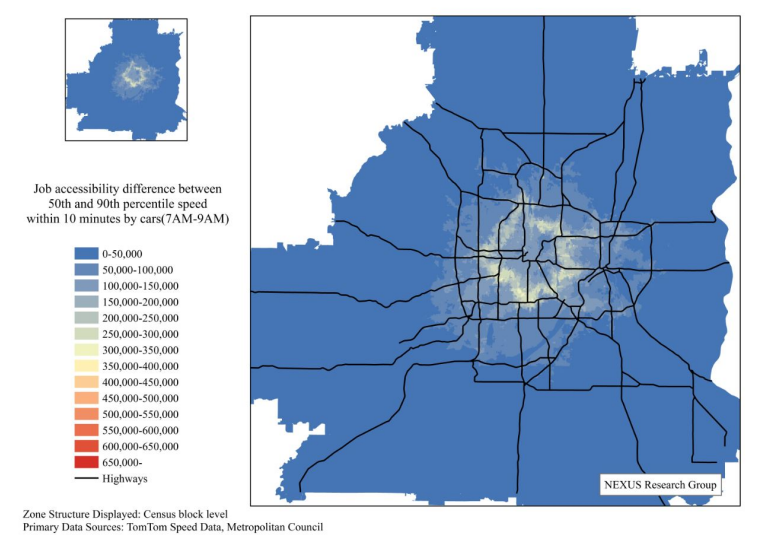

(a) The ring of unreliability in 10 minutes

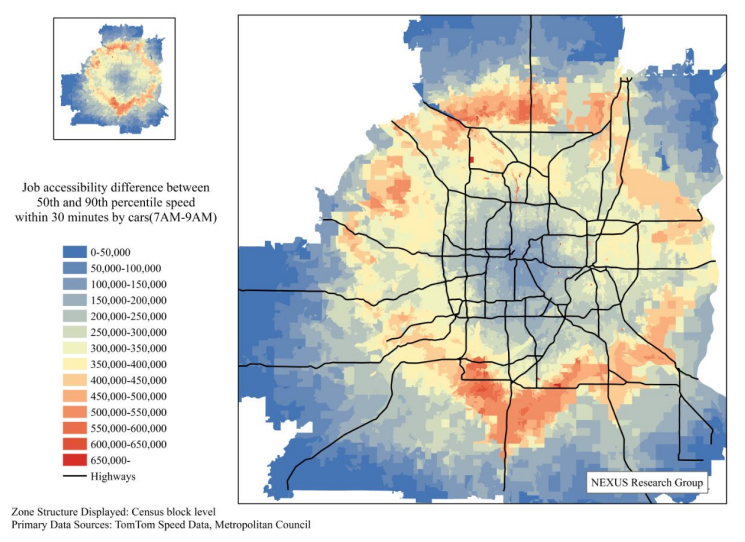

(c) The ring of unreliability in 30 minutes

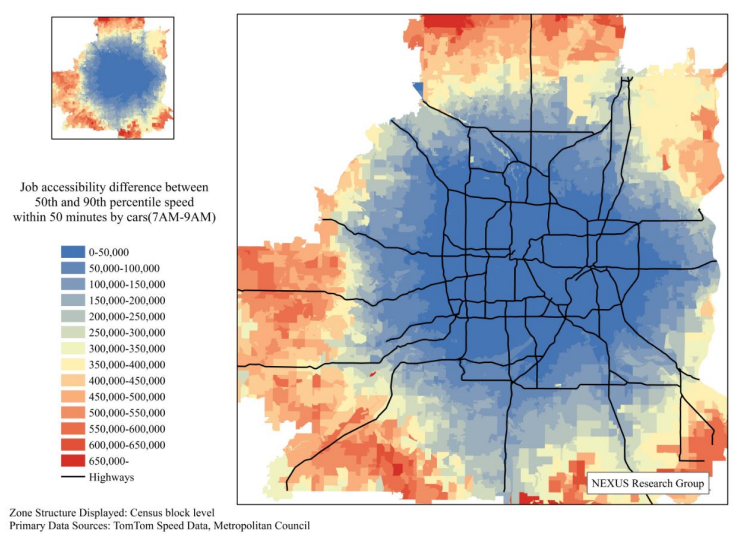

(e) The ring of unreliability in 50 minutes

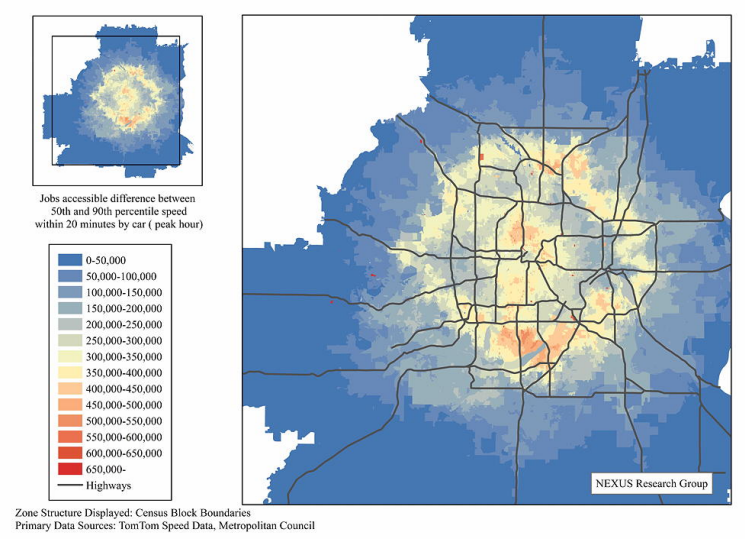

(b) The ring of unreliability in 20 minutes

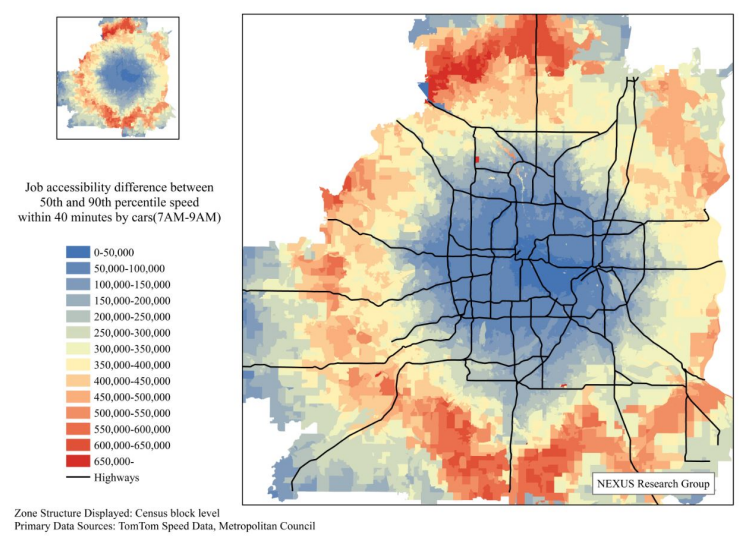

(d) The ring of unreliability in 40 minutes

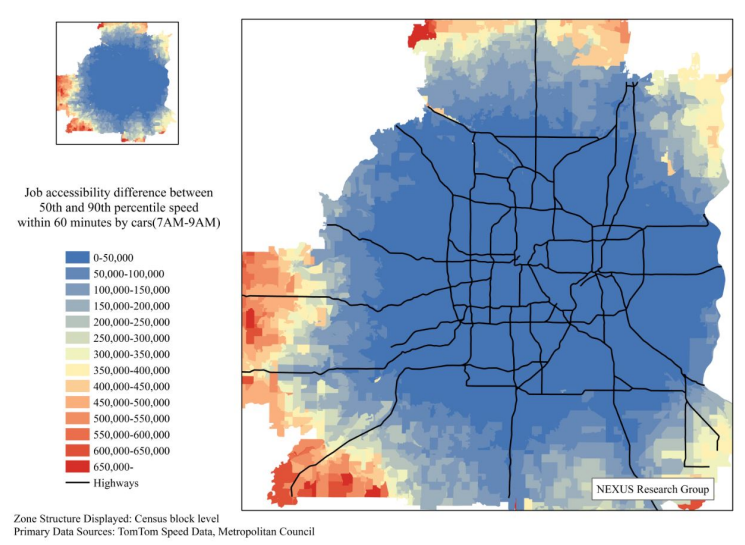

(f) The ring of unreliability in 60 minutes

FIGURE 5 : The ring of unreliability in different time thresholds from 10 minutes to 60 minutes 
1 around the down town area, and has the similar location as differences in 20 minutes.

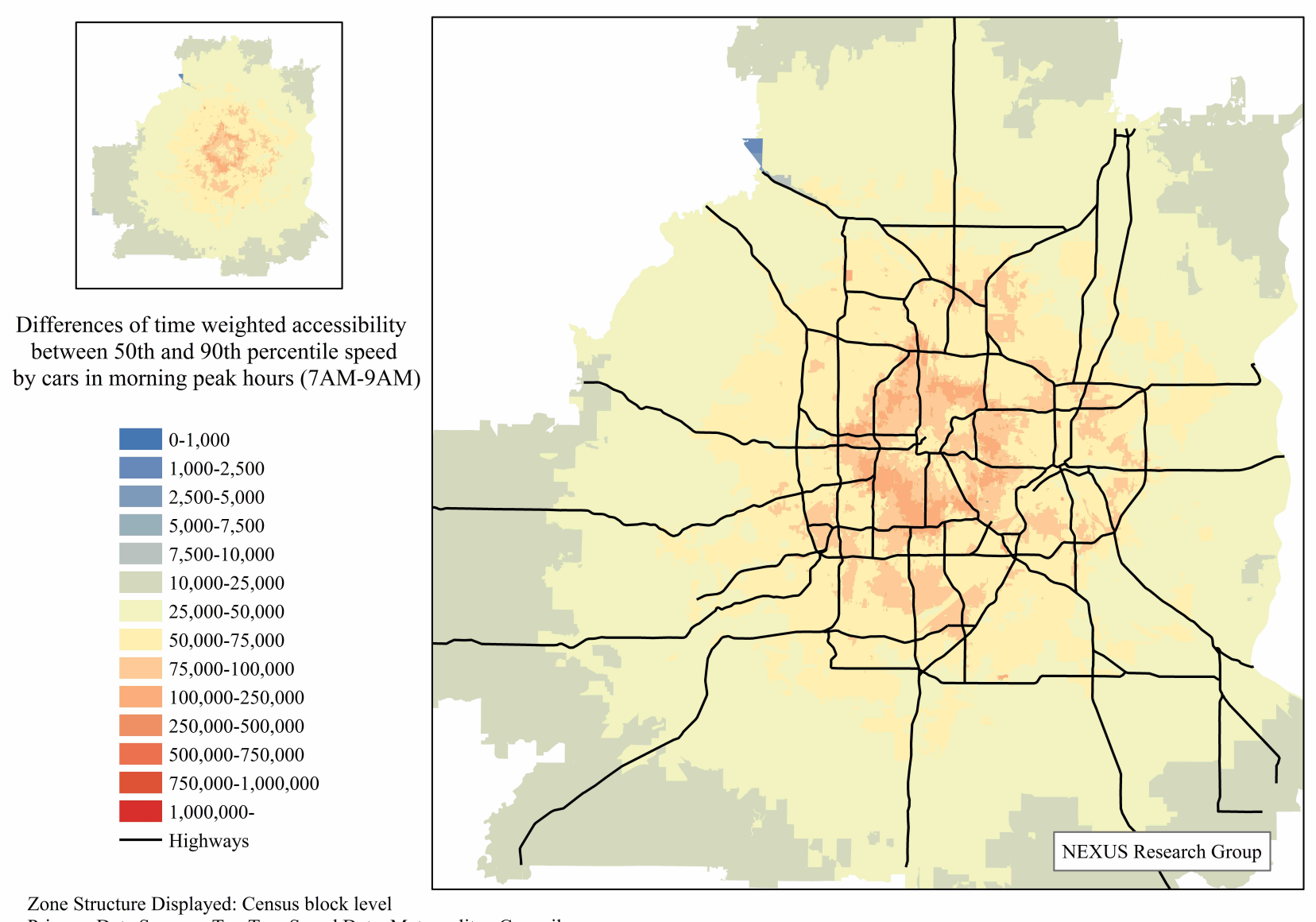

Primary Data Sources: TomTom Speed Data, Metropolitan Council

FIGURE 6 : The time weighted difference of job accessibility between 50th and 90th percentile speeds

We conjecture the following reasons, which will be tested in future research:

1. People living in the outer suburbs use freeways for a larger proportion of their travel, particularly to work than those in the core cities and inner suburbs.

2. Freeways are more vulnerable to incidents than a connected arterial network because their limited access and egress points and expect to see that freeways have a wider percentage variation in travel times than arterials.

3. The very economy of scale that results in freeways having a lower average travel time (higher speed) makes them less reliable and more vulnerable to incidents. 


\section{CONCLUSION}

2 This study measured the accessibility to jobs in the Twin Cities region based on the TomTom road

3 speed network data for 2010 and illustrated how accessibility to jobs changes at different time 4 thresholds and speed percentiles on the road network.

First, job accessibility measurement in the Twin Cities has a clear distribution pattern that the downtown area has higher job accessibility, while suburban area has lower one.

Second, time threshold is an important parameter for measuring accessibility when using the cumulative opportunity measure. The influence pattern is as expected, in that a larger time threshold results in higher accessibility.

Third, job accessibility measurement depends significantly on the speed on the road network. Higher speeds increase the number of job opportunities that can be reached in a given time. This result reflects an efficient way to increase the job accessibility that is to improve the speed on the road network.

Fourth, the difference in job accessibility at different percentile speeds displays a prominent ring pattern in different time thresholds, with the greatest loss in job accessibility found in a ring around the center of the region. Time threshold affects the graphical distribution of the ring. A higher time threshold causes a ring farther from the downtown area. The differences in timeweighted accessibility to jobs also show the ring clearly around the center area, which is similar to the patterns in 20 minutes. The existence of the ring is associated with an increased dependence on freeways for travel in lieu of local streets. The network connectivity in the second, third, and fourth ring suburbs is typically lower than in central cities (and older first ring suburbs). Thus it is more vulnerable to incidents, as it is more highly channelized, and this is reflected in the large differences in accessibility for 10th and 90 percentile speeds. We dub this the "Ring of Unreliability".

This study only considered the morning peak period, future study should examine other periods of the day and particularly peak vs. non-peak periods, to see if the "Ring of Unreliability" remains. More complex accessibility measures can be considered to see whether this relationship remains with a composite (weighted cumulative opportunity) accessibility measure, rather than just at a single time threshold. We hypothesize the pattern will remain, but this needs to be tested.

Future research will try to explain the reliability of accessibility at the origin level as a function of specific network structure characteristics, such as circuity and connectivity.

\section{REFERENCES}

[1] Science Applications International Corporation (SAIC), Delcan Corporation and University of Virginia., Evaluation of Utilizing Probe-based Freight Data to Support Congestion Monitoring on the Highway System, Results and Initial Conclusions Summary. Federal Highway Administration, 2012.

[2] Liao, C.-F., Generate Reliable Freight Performance Measures Using Truck GPS Data - A Case Study in Twin Cities Metropolitan Area, Minnesota. Transportation Research Record: Journal of the Transportation Research Board, Vol. (in press), 2014.

[3] Anderson, P., A. Owen, and D. Levinson, The Time Between: Continuously-defined accessibility functions for schedule-based transportation systems, 2012.

[4] Zhu, S. and D. Levinson, People don't use the shortest path. In 12th Conference of the International Association for Travel Behaviour Research, Jaipur, India, 2009. 
[5] Sheffi, Y., The resilient enterprise: overcoming vulnerability for competitive advantage. The MIT Press, 2005.

[6] Ortiz, D. S., B. Weatherford, H. H. Willis, M. Collins, N. Mandava, and C. Ordowich, Increasing the capacity of freight transportation: US and Canadian perspectives, Vol. 228. Rand Corporation, 2007.

[7] Ortiz, D. S., L. Ecola, and H. H. Willis, Freight Transportation Resilience: How a systemwide perspective can help MPOs and DOT. NCHRP - Transportation Research Board of the National Academies, Washington, DC, 2009.

[8] Federal Highway Administration, Statewide Opportunities for Linking Planning and Operations: A Primer. US Department of Transportation, 2008.

[9] Garrison, W. L. and D. F. Marble, The Structure of Transportation Networks. Transportation Center at Northwestern University, Evanston, Ill., 1961, draft of a report submitted October 31, 1961 to U.S. Army Transportation Research Command, Fort Eustis, Virginia, by the Transportation Center at Northwestern University under contract DA-44-177-TC-685, Transportation geography study.

[10] Kansky, K., Structure of Transportation Networks: Relationships Between Network Geometry and Regional Characteristics. Ph.D. thesis, University of Chicago, 1963, research Paper No. 84 .

[11] Kissling, C., Linkage Importance in a Regional Highway Network. The Canadian Geographer, Vol. 13, No. 2, 1969, pp. 113-127.

[12] Taaffe, E., H. Gauthier, and E. Morton, Geography of Transportation. Prentice-Hall, Upper Saddle River, NJ, 1996.

[13] Gauthier, H. L., Highway development and urban growth in Sao Paulo, Brazil: a network analysis. Ph.D. thesis, Northwestern University, 1966.

[14] Rodrigue, J.-P., C. Comtois, and B. Slack, The Geography of Transport Systems. Routledge, London; New York, 2006.

[15] Haggett, P. and R. Chorley, Network analysis in geography. Edward Arnold, London, U.K., 1969.

[16] Gastner, M. and M. Newman, The spatial structure of networks. The European Physical Journal B-Condensed Matter and Complex Systems, Vol. 49, No. 2, 2006, pp. 247-252.

[17] Barthélemy, M., Spatial networks. Physics Reports, Vol. 499, No. 1, 2011, pp. 1-101.

[18] Patuelli, R., A. Reggiani, P. Nijkamp, and F. Bade, The evolution of the commuting network in Germany: Spatial and connectivity patterns. Journal of Transport and Land Use, Vol. 2, No. 3/4, 2010, pp. 5-37.

[19] Levinson, D. and A. El-Geneidy, The minimum circuity frontier and the journey to work. Regional Science and Urban Economics, Vol. 39, No. 6, 2009, pp. 732-738. 
1 [20] Parthasarathi, P., H. Hochmair, and D. Levinson, Network structure and spatial separation. Environment and Planning B, Planning and Design., Vol. 39, No. 1, 2012, pp. 137-154.

3 [21] Parthasarathi, P., D. Levinson, and H. Hochmair, Network structure and travel time perception. PloS one, Vol. 8, No. 10, 2013, p. e77718.

[22] Yang, C., Y. Tu, and X. Chen, Analysis Method for Topology Vulnerability of Transportation Network. In Proceedings of the Second International Conference on Transportation Engineering (Q. Peng, K. C. P. Wang, and Y. Qiu, eds.), ASCE, Reston, VA, 2009, pp. 3639-3644.

[23] Jenelius, E., Network structure and travel patterns: Explaining the geographical disparities of road network vulnerability. Journal of Transport Geography, Vol. 17, No. 3, 2009, pp. 234-244.

[24] Rodríguez-Núñez, E. and J. C. García-Palomares, Measuring the vulnerability of public transport networks. Journal of Transport Geography, Vol. 35, 2014, pp. 50-63.

[25] Marshall, W. and N. Garrick, Street network types and road safety: A study of 24 California cities. Urban Design International, Vol. 15, 2010, pp. 133-147.

[26] Townsend, A., Re-Programming Mobility: How the Tech Industry Is Driving Us Towards A Crisis in Transportation Planning. New Cities Foundation, 2012.

[27] Levinson, D. and B. Yerra, Self Organization of Surface Transportation Networks. Transportation Science, Vol. 40, No. 2, 2006, pp. 179-188.

[28] Yerra, B. M. and D. M. Levinson, The emergence of hierarchy in transportation networks. The Annals of Regional Science, Vol. 39, No. 3, 2005, pp. 541-553.

[29] Cervero, R., Paradigm shift: from automobility to accessibility planning. Working Paper 677, 1996.

[30] Cheng, J. and L. Bertolini, Measuring urban job accessibility with distance decay, competition and diversity. Journal of Transport Geography, 2013.

[31] El-Geneidy, A. M. and D. M. Levinson, Access to Destinations: development of accessibility measures. Minnesota Department of Transportation Research Services Section, 2006.

[32] Hansen, W. G., How accessibility shapes land use. Journal of the American Institute of Planners, 1959.

[33] Levinson, D. M., Accessibility and the journey to work. Journal of Transport Geography, 1998.

[34] Martellato, D. and P. Nijkamp, The concept of accessibility revisited. Accessibility, Trade and Locational Behaviour, Ashgate, Brookfield, 1998.

[35] Owen, A. and D. Levinson, Access to Destinations: Annual accessibility measure for the Twin Cities Metropolitan Region. Minnesota Department of Transportation Research Services Section, 2012. 
1 [36] Páez, A., D. M. Scott, and C. Morency, Measuring accessibility: positive and normative

2

4 [37] TomTom International BV, Speed Profiles, ????

5 [38] US Census Bureau, TIGER/Line Shapefiles, 2010.

6 [39] US Census Bureau, LEHD origin-destination employment statistics dataset structure format 7 implementations of various accessibility indicators. Journal of Transport Geography, Vol. 25, 2012, pp. 141-153. version 7.0., 2013.

[40] Vickerman, R. W., Accessibility, attraction, and potential: a review of some concepts and their use in determining mobility. Environment and Planning, 1974.

[41] Wachs, M. and T. G. Kumagai, Physical accessibility as a social indicator. Socio-Economic Planning Sciences, 1973.

[42] Demographia, Demographia United States Central Business Districts (Downtown): With data for selected additional employment areas: 3rd Edition, 2014.

[43] Anderson, P., D. Levinson, and P. Parthasarathi, Accessibility Future. Transaction in GIS, 2013. 